\title{
COMPREHENSIVE ANALYSIS OF WIRE ELECTRIC DISCHARGE MACHINING PROCESS IN MACHINING HIGH CHROMIUM HIGH CARBON STEEL
}

\author{
S. DINESH, A. GODWIN ANTONY, K. RAJAGURU, \& P. PARAMESWARAN
}

Assistant Professor, Department of Mechanical Engineering, K. Ramakrishnan College of Technology,

Kariyamanikam Road, Samayapuram, Tiruchirappali, Tamil Nadu, India

Every manufacturing industry primarily concentrates on yielding maximum profit with minimal expenditure where profit directly depends on the production cost and quality of the product. The firm aims at maximum production rate with minimum production cost and maximum surface quality. The minimal production cost and surface finish can be achieved by proper selection of combination of machining parameters, interaction study between of machining parameters and identification of the most contributing parameter for a specific response. Modern manufacturing industries have adopted different advanced machining processes for machining hard and difficult to machine materials. Wire Electric Discharge Machining process is the most adopted when considering machining of rectangle contour profile. The work mainly reflects on performance analysis of machining parameters in producing different contour shapes using Wire Electric Discharge Machining parameters. The consequence of the Machining parameters such as Pulse ON time, Pulse OFF time and MAO over the Machining time and Surface Roughness has been analyzed. The interaction study is made by Response Surface methodology. Analysis of Variance is used to identify the most significant parameters for the respective responses. The MAO had greater impact on Surface Roughness followed by Pulse ON time. The Pulse ON time was encountered as the most contributing parameter, for Machining Time. The average deviation between the empirical and predicted model for surface roughness was recorded as $0.03 \%$, whereas $\mathbf{0 . 0 2 3 \%}$ deviation was observed for Machining time. The regression model was developed for both Surface roughness and Machining time. Validation of models proved that, the developed models can be used to predict the responses.

KEYWORDS: Wire Electric Discharge Machining, Machining Time, Surface Roughness, Contour Profile, Response Surface Methodology \& Analysis of Variance
\end{abstract}

Received: Nov 20, 2017; Accepted: Dec 11, 2017; Published: Dec 22, 2017; Paper Id.: IJMPERDFEB20187

\section{INTRODUCTION}

Aniza Alias et al. [1], gave the most feasible combination of machining parameters for machining Ti-6Al$4 \mathrm{~V}$ with brass wire, by varying the machine feed rate and proved that, machine feed rate had a significant effect on the kerf width and surface texture. Anshuman Kumar et al. [2], proved the proposed numerical model can be used for analyzing the effects of the contributing parameters over temperature distribution and Material Removal rate. Also, Pulse ON time was identified as the major contributing parameter for the outputs. Farnaz Nourbakhsh et al. [3] studied the micro structural characteristics of the machined work piece, to understand the impact of using different wires to machine it and ANOVA was made to identify the most significant parameter. Jarin et al. [4] studied the effect of addition of nano powders, to dielectric medium to machine gold coated silicon wafer and inferred that, the addition of nano powder improved the machining efficiency. Nagabhushana Ramesh et al. [5] machined titanium and High Speed Steel, by modifying the WEDM setup for sawing purpose and proved that, the 
WEDM can be used, for sawing by comparing the microstructure of the machined workpiece, using SEM images. Nilesh G. Patil et al. [6] showed that, the surface roughness of the machined product was increased with increase in alumina fraction and was decreased with increase in SiC fraction, in Aluminium Composites reinforced with ceramic particles. SEM images showed that, the reinforcement of ceramic particles had great effect on the composites. Raju et al. [7] suggested a regression model, to predict the surface roughness and showed that, Pulse ON time was the major contributing parameter for surface roughness. Pragya Shandilya et al. [8] proved that, voltage and wire feed rate had a greater effect on Kerf width in machining Aluminium composites reinforced with SiC powders and the surface roughness was improved, while machining with lower levels of the contributing parameters. SEM analysis showed that, craters and black patches in machined surface. Pujari Srinivasa Rao et al. [9], predicted the residual stress in machining Aluminium 2014 T 6 alloy as 8.2 to $405.6 \mathrm{MPa}$ and proved that, there was no surface cracks formed in microstructure study while compared to other materials. Ravindranadh Bobbili et al. [10] revealed that, the brass wire broke with the increased wear rate due to increase in input energy and depicted the formation of craters, debris and micro cracks. Zhe Chen et al. [11] depicted that, the Inconel 718 had reduced fatigue life, when machined using wire and the cracks originated, from the already existing defects. Suresh Kumar et al. [12], compared the machining efficiency of drilling titanium grade 2 materials, with coated and non coated carbide tools. Suresh Kumar et al. [13], used response surface methodology, to analyze the effect of drilling parameters over the thrust force and surface roughness, in machining titanium alloy.

\section{EXPERIMENTATION}

The contributing parameters that are used for the analysis of effect, on machining time and surface roughness are Pulse ON time, Pulse OFF time and MAO. Taguchi's L16 mixed array is used for identifying the minimum number of combinations required for experimentation. Pulse ON and Pulse OFF time are chosen, in four stages ranging from 8 seconds to 14 seconds and 15 to 37 seconds. MAO is chosen in two levels, $270 \mathrm{~m} / \mathrm{min}$ and $280 \mathrm{~m} / \mathrm{min}$. The range of machining parameters is shown in table 1 . Rectangular slot of $10 \times 5 \mathrm{~mm}$ was made on $6 \mathrm{~mm}$ thick plate, with ACCUTEX EX-43SA machine.

Table 1: Range of Contributing Parameters

\begin{tabular}{|l|c|c|c|c|}
\hline \multicolumn{1}{|c|}{ Contributors/ Stage } & Stage 1 & Stage 2 & Stage 3 & Stage 4 \\
\hline Pulse ON time (seconds) & 8 & 10 & 12 & 14 \\
\hline Pulse OFF time (seconds) & 15 & 22 & 30 & 37 \\
\hline MAO (m/min) & 270 & 280 & - & - \\
\hline
\end{tabular}

L16 mixed level array is used for experimentation and the outcomes are shown in table 2.

Table 2: Empirical Outcomes

\begin{tabular}{|c|c|c|c|c|c|}
\hline $\begin{array}{c}\text { Trail } \\
\text { Number }\end{array}$ & $\begin{array}{c}\text { Pulse ON } \\
\text { Time (sec) }\end{array}$ & $\begin{array}{c}\text { Pulse OFF } \\
\text { Time (sec) }\end{array}$ & MAO (m/min) & $\begin{array}{c}\text { Machining } \\
\text { Time (sec) }\end{array}$ & $\begin{array}{c}\text { Surface Roughness } \\
\text { (microns) }\end{array}$ \\
\hline 1 & 8 & 15 & 270 & 11.55 & 1.73 \\
\hline 2 & 8 & 22 & 270 & 12.1 & 1.34 \\
\hline 3 & 8 & 30 & 280 & 16.28 & 2.04 \\
\hline 4 & 8 & 37 & 280 & 15.4 & 1.91 \\
\hline 5 & 10 & 15 & 270 & 11.3 & 1.84 \\
\hline 6 & 10 & 22 & 270 & 11.35 & 1.73 \\
\hline 7 & 10 & 30 & 280 & 14.31 & 2.09 \\
\hline 8 & 10 & 37 & 280 & 15.23 & 2.14 \\
\hline 9 & 12 & 15 & 280 & 9.29 & 2.32 \\
\hline 10 & 12 & 22 & 280 & 9.76 & 2.1 \\
\hline
\end{tabular}




\begin{tabular}{|c|c|c|c|c|c|}
\hline \multicolumn{7}{|c|}{ Table 2 Contd., } \\
\hline 11 & 12 & 30 & 270 & 11.79 & 2.05 \\
\hline 12 & 12 & 37 & 270 & 13 & 1.88 \\
\hline 13 & 14 & 15 & 280 & 8.9 & 2.27 \\
\hline 14 & 14 & 22 & 280 & 9.31 & 2.05 \\
\hline 15 & 14 & 30 & 270 & 11.26 & 2.09 \\
\hline 16 & 14 & 37 & 270 & 12.36 & 2.31 \\
\hline
\end{tabular}

Effect of Contributing Parameters over Machining Time

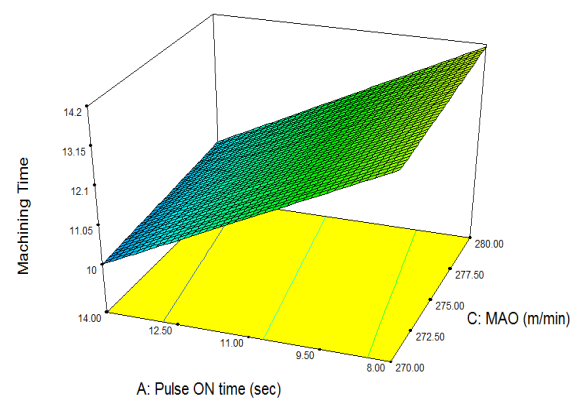

Figure 1: Effect of Pulse ON and MAO over Machining Time

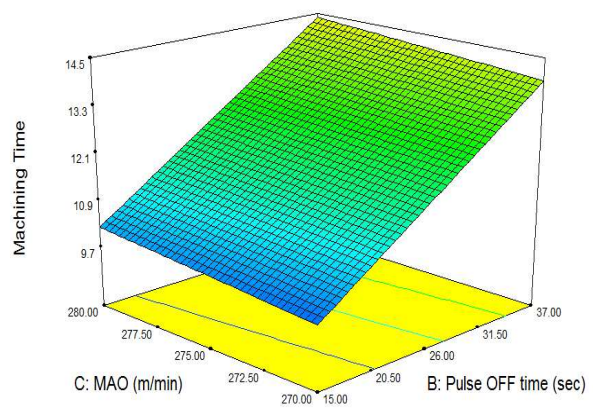

Figure 2: Effect of MAO and Pulse OFF Time over Machining Time

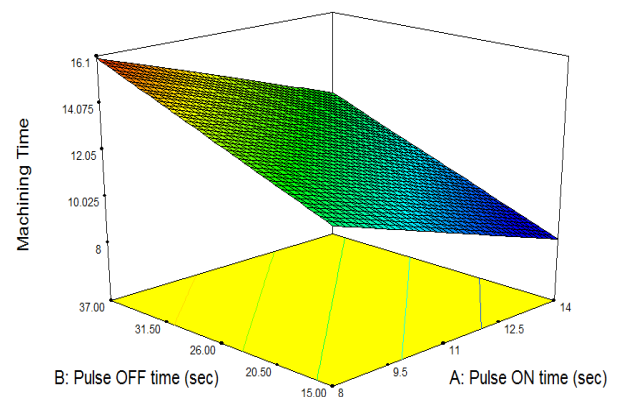

Figure 3: Effect of Pulse ON and Pulse OFF Time over Machining Time

The impact of Pulse ON and MAO on Machining time is shown in figure 1, where the Maximum Machining time is encountered at maximum MAO of $280 \mathrm{~m} / \mathrm{min}$ and at minimum Pulse ON time of 8 seconds. The least machining time for the model was identified at maximum Pulse ON time and minimum MAO of 14 seconds and $270 \mathrm{~m} / \mathrm{min}$. The machining time tends to increase linearly. 
The authority of MAO and Pulse OFF time over is plotted in figure 2, which shows that the minimum Machining time is recorded at minimal MAO and Pulse OFF time $(270 \mathrm{~m} / \mathrm{min}$ and 15 seconds). The machining time rises linearly with raise in Pulse OFF time and MAO. Maximum machining time was recorded at maximum Pulse OFF time and MAO (37 seconds and $280 \mathrm{~m} / \mathrm{min})$.

The dominance of Pulse ON time and Pulse OFF time is showcased, in the figure 3. The least Machining time was recorded at maximum Pulse ON time of 14 seconds and minimum Pulse OFF time of 15 seconds. The peak value of Machining time was encountered, at maximum Pulse OFF time of 37 seconds and least Pulse ON time 8 seconds. The machining time tends to vary linearly with Pulse ON and Pulse OFF time.

\section{Effect of Contributing Parameters over Surface Roughness}

Figure 4 dictates the impact of Pulse ON time and Pulse OFF time, over Surface Roughness. It is noted that, the maximum Surface Roughness is obtained at maximum Pulse ON and Pulse OFF time. The minimum Surface Roughness is identified at maximum Pulse OFF and minimum Pulse ON time. The pulse ON time ranges from 8 to 14 seconds, whereas Pulse OFF from 15 to 37 seconds.

The variation in surface roughness with MAO and Pulse ON time is demonstrated in figure 5. Maximum Pulse ON time and minimum MAO had the maximum Surface Roughness and the minimum surface roughness was encountered at minimum MAO and minimum Pulse On time.

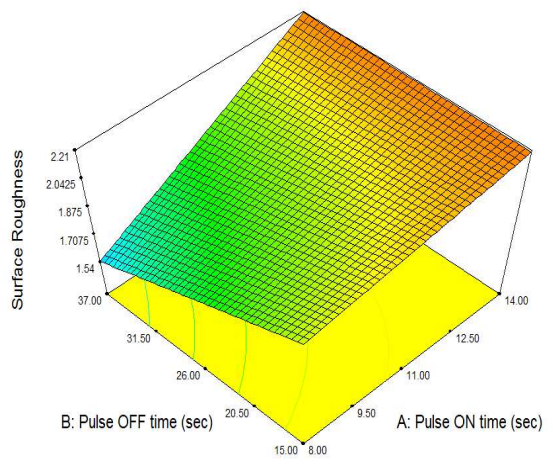

Figure 4: Pulse ON Time and Pulse OFF Time (vs.) Surface Roughness

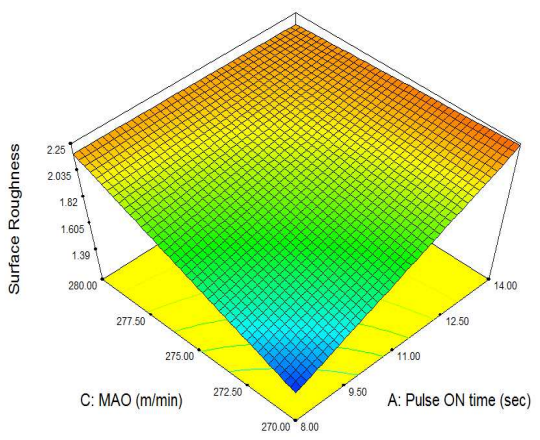

Figure 5: MAO and Pulse OFF Time (vs.) Surface Roughness

Figure 6 dictates the effect of MAO and Pulse OFF time, over Surface Roughness. The least possible Surface roughness was recorded at maximum Pulse OFF time and minimum MAO, whereas the maximum Surface roughness was encountered at maximum MAO and minimum Pulse OFF time. 


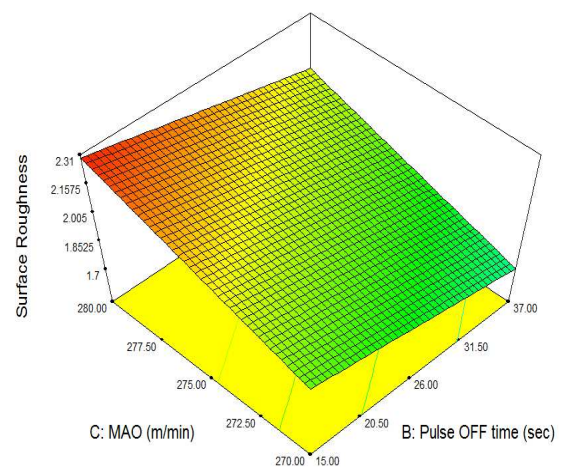

Figure 6: MAO and Pulse OFF Time (vs.) Surface Roughness

\section{Analysis by Variance for Machining Time and Surface Roughness}

The ANOVA table for Machining Time and Surface Roughness is shown in table 3 and 4.

Table 3: ANOVA Table for Machining Time

\begin{tabular}{|l|c|c|c|c|c|c|}
\hline \multicolumn{1}{|c|}{ Source } & SS & DF & MS & F & P & Status \\
\hline Model & 70.5456 & 3 & 23.5152 & 39.9272 & $<0.0001$ & significant \\
\hline A-Pulse ON time & 29.829 & 1 & 29.829 & 50.6477 & $<0.0001$ & \\
\hline B-Pulse OFF time & 39.8282 & 1 & 39.8282 & 67.6256 & $<0.0001$ & \\
\hline C-MAO & 0.88831 & 1 & 0.88831 & 1.50828 & 0.2429 & \\
\hline Residual & 7.06742 & 12 & 0.58895 & & & \\
\hline Cor Total & 77.613 & 15 & & & & \\
\hline
\end{tabular}

The model seems to be significant at F-value of 39.9272. The possibility of "Model F- Value "to be this larger due to noise is $0.01 \%$. The parameters seem to be significant since the Values of "Prob > F" less than 0.0500. The "Adj RSquared" is of 0.8862 , the ratio of 20.478 shows that, the model can be used for investigation of machining time.

Table 4: ANOVA Table for Surface Roughness

\begin{tabular}{|l|c|c|c|c|c|c|}
\hline \multicolumn{1}{|c|}{ Source } & SS & DF & MS & F & P & Status \\
\hline Model & 0.822646 & 6 & 0.137108 & 9.499571 & 0.0018 & significant \\
\hline A-Pulse ON time & 0.131686 & 1 & 0.131686 & 9.123939 & 0.0145 & \\
\hline B-Pulse OFF time & 0.044056 & 1 & 0.044056 & 3.052411 & 0.1146 & \\
\hline C-MAO & 0.172292 & 1 & 0.172292 & 11.93734 & 0.0072 & \\
\hline AB & 0.025545 & 1 & 0.025545 & 1.769908 & 0.2161 & \\
\hline AC & 0.136791 & 1 & 0.136791 & 9.477616 & 0.0132 & \\
\hline BC & $7.69 \mathrm{E}-05$ & 1 & $7.69 \mathrm{E}-05$ & 0.005325 & 0.9434 & \\
\hline Residual & 0.129897 & 9 & 0.014433 & & & \\
\hline Cor Total & 0.952544 & 15 & & & & \\
\hline
\end{tabular}

Note: $\mathbf{D F}=$ Degrees of freedom; $\mathbf{S S}=$ Sum of squares; $\mathbf{M S}=$ Mean squares; $\mathbf{F}=$ F-value; $\mathbf{P}=\mathrm{P}$-value.

The model seems to be significant at F-value of 9.499571. The possibility of "Model F- Value "to be this larger due to noise is $0.018 \%$. The parameters seem to be significant since the Values of "Prob > F" less than 0.0500. The "Adj RSquared" is of 0.77 . The ratio of 9.695 shows that, the model can be used for investigation of Surface Roughness

\section{Regression Analysis}

The regression model for Machining time and Surface roughness is shown in equ (1) and equ (2), which shows the relationship within the contributing parameters and the responses. 
Machining Time $=0.87551-(0.61062$ : Pulse 0N time $)+(0.19063:$ Pulse OFF time $)+(0.047125:$

MAO)

Surface Roughness $=-50.53594+(3.85634 *$ Pulse ON time $)-(0.026505 *$ Pulse OFF time $)+$ $(0.19210 *$ MAO $)+(3.68617 E-0.003 *$ Pulse ON time *Pulse OFF time $)-(0.014120 *$

Pulse ON time $*$ MAO) $-(9.04255 E-0.005 *$ Pulse OFF time $*$ MAO) equ (2)

Comparision of Predicted and Experimental Value of Machining Time

Table 5: Predicted vs Experimental Machining Time

\begin{tabular}{|c|c|c|}
\hline $\begin{array}{c}\text { Trail } \\
\text { Number }\end{array}$ & $\begin{array}{c}\text { Machining } \\
\text { Time (sec) }\end{array}$ & $\begin{array}{c}\text { Predicted Machining } \\
\text { Time (sec) }\end{array}$ \\
\hline 1 & 11.55 & 11.57 \\
\hline 2 & 12.1 & 12.91 \\
\hline 3 & 16.28 & 14.90 \\
\hline 4 & 15.4 & 16.24 \\
\hline 5 & 11.3 & 10.35 \\
\hline 6 & 11.35 & 11.69 \\
\hline 7 & 14.31 & 13.68 \\
\hline 8 & 15.23 & 15.02 \\
\hline 9 & 9.29 & 9.60 \\
\hline 10 & 9.76 & 10.94 \\
\hline 11 & 11.79 & 11.99 \\
\hline 12 & 13 & 13.33 \\
\hline 13 & 8.9 & 8.38 \\
\hline 14 & 9.31 & 9.72 \\
\hline 15 & 11.26 & 10.77 \\
\hline 16 & 12.36 & 12.10 \\
\hline
\end{tabular}

Table 5 and Figure 7 shows the comparison between the predicted and experimental readings. The average diversion between the empirical and predicted values of machining time was recorded as $0.023 \%$. This acknowledges the fact that the developed model can be used for prediction of Machining Time.

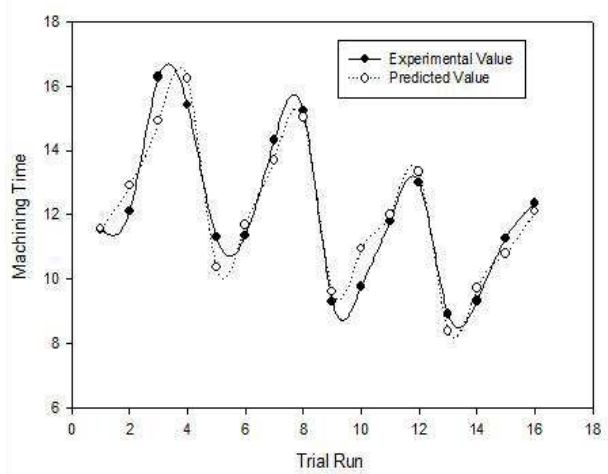

Figure 7: Predicted vs Experimental Machining Time 
Comparison of Predicted and Experimental Value of Machining Time

Table 6: Predicted vs. Experimental Surface Roughness Values

\begin{tabular}{|c|c|c|}
\hline $\begin{array}{c}\text { Trail } \\
\text { Number }\end{array}$ & $\begin{array}{c}\text { Surface } \\
\text { Roughness } \\
\text { (Microns) }\end{array}$ & $\begin{array}{c}\text { Predicted } \\
\text { Surface } \\
\text { Roughness } \\
\text { (Microns) }\end{array}$ \\
\hline 1 & 1.73 & 1.63 \\
\hline 2 & 1.34 & 1.48 \\
\hline 3 & 2.04 & 2.08 \\
\hline 4 & 1.91 & 1.93 \\
\hline 5 & 1.84 & 1.83 \\
\hline 6 & 1.73 & 1.73 \\
\hline 7 & 2.09 & 2.11 \\
\hline 8 & 2.14 & 2.01 \\
\hline 9 & 2.32 & 2.25 \\
\hline 10 & 2.1 & 2.20 \\
\hline 11 & 2.05 & 1.93 \\
\hline 12 & 1.88 & 1.88 \\
\hline 13 & 2.27 & 2.17 \\
\hline 14 & 2.05 & 2.17 \\
\hline 15 & 2.09 & 2.24 \\
\hline 16 & 2.31 & 2.24 \\
\hline
\end{tabular}

The model is suggested to predict the Surface Roughness, as the average deviation between predicted and empirical values are almost zero i.e. $0.03 \%$. The model was validated and table 6 presents the predicted and experimental values, for Surface Roughness. Figure 8 and table 6, shows the Predicted vs Experimental surface roughness values.

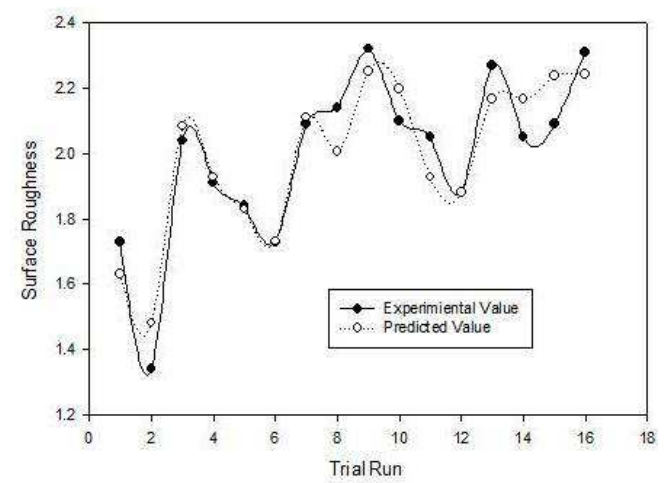

Figure 8: Predicted vs Experimental Surface Roughness

\section{CONCLUSIONS}

The following inferences are made from the analysis of the developed model, with the help of Response surface Methodology and Regression Analysis.

- The machining time has reduced in linear form with reference to Pulse ON time and it was observed that, the Surface Roughness was increased in linear fashion with increase in MAO.

- The regression model was developed for both Surface roughness and Machining time. Validation of models proved that the developed models can be used to predict the responses. 
- The average deviation between the empirical and predicted model, for surface roughness was recorded as $0.03 \%$ whereas $0.023 \%$ deviation was observed for Machining time.

- The MAO had greater impact on Surface Roughness followed by Pulse ON time. The Pulse ON time was encountered as the most contributing parameter for Machining Time.

\section{REFERENCES}

1. Aniza Alias, Bulan Abdullah, Norliana Mohd Abbas,' WEDM: Influence of Machine Feed Rate in Machining Titanium Ti-6Al4V Using Brass Wire and Constant Current (4A)', Procedia Engineering 41 (2012) 1812 - 1817.

2. Anshuman Kumar, Dillip Kumar Bagal, Maity. K. P,' Numerical Modeling of Wire Electrical Discharge Machining of Super alloy Inconel 718', Procedia Engineering 97 (2014) 1512 - 1523.

3. Farnaz Nourbakhsh, K. P. Rajurkar, A. P. Malshe, Jian Cao, 'Wire electro-discharge machining of titanium alloy', Procedia CIRP 5 ( 2013$) 13-18$.

4. S. B. Chikalthankar, V. M Nandedkar \& S. V Borde, Influence of Machining Parameters on Electric Discharge Machining of WPS Tool Steels "An Experimental Investigation", International Journal of Mechanical and Production Engineering Research and Development (IJMPERD), Volume 3, Issue 5, November - December 2013, pp. 21-28

5. Jarin. S, Saleh. T, Rana. M, Muthalif. A. G. A, Ali. M. Y, 'An Experimental Investigation on the Effect of Nano powder for Micro-Wire Electro Discharge Machining of Gold Coated Silicon', Procedia Engineering 184 (2017) 171 - 177.

6. Nagabhushana Ramesh. N, Kalley Harinarayana, Balu Naik. B,' Machining Characteristics of H.S.S. \& Titanium Using Electro Discharge Sawing and Wire - Electro discharge Machining', Procedia Materials Science 6( 2014) 1253 - 1259.

7. Qasim Bader, Effect of V Shape Notch Location on Fatigue Life in Steel Beam Made of Carbon Steel Alloys with Different Content of Carbon, International Journal of Mechanical and Production Engineering Research and Development (IJMPERD), Volume 4, Issue 4, July - August 2014, pp. 69-78

8. Nilesh G. Patila, Brahmankar. P.K,' Semi-empirical modeling of surface roughness in wire electro-discharge machining of ceramic particulate reinforced Al matrix composites', Procedia CIRP 42 ( 2016 ) 280 - 285.

9. Raju.P, Sarcar. MMM, Satyanarayana.B,'Optimization of Wire Electric Discharge Machining Paramters for Surface Roughness on 316 L Stainless Steel Using Full Factorial Experimental Design', Proceedia Materials Science 5 (2014) 1670 1676.

10. Pragya Shandilya, Jain P.K, Jain N.K,' Parametric optimization during wire electrical discharge machining using response surface methodology', Procedia Engineering 38 ( 2012 ) 2371 - 2377.

11. Pujari Srinivasa Rao, Koona Ramji, Beela Satyanarayana,' Effect of wire EDM conditions on generation of residual stresses in machining of aluminum 2014 T6 alloy', Alexandria Engineering Journal (2016) 55, 1077-1084.

12. Ravindranadh Bobbili, Madhu. V, Gogia A.K,' An experimental investigation of wire electrical discharge machining of hotpressed boron carbide', Defence Technology 11 (2015) 344-349.

13. Zhe Chen, Johan Moverare, Ru Lin Peng, Sten Johansson,' Surface Integrity and Fatigue Performance of Inconel 718 in Wire Electrical Discharge Machining,' Procedia CIRP 45 ( 2016 ) 307 - 310.

14. L.O. Osoba, I.C. Ekpe \& R.A. Elemuren, Analysis of Dissimilar Welding of Austenitic Stainless Steel to Low Carbon Steel by TIG Welding Process, International Journal of Metallurgical \& Materials Science and Engineering, Volume 5, Issue 5, September - October 2015, pp. 1-12 

Machining High Chromium High Carbon Steel

15. Suresh kumar. B, Vijayan. V, Baskar. $N$ 'Comparison of coated and uncoated carbide drill bits for drilling titanium grade 2 material', Mechanika 22(6) (2016) 571-575..

16. Suresh kumar. B, Baskar. N, 'Integration of fuzzy logic with response surface methodology for thrust force and surface roughness modeling of drilling on titanium alloy', International Journal of Advanced Manufacturing Technology 65 (2013) $1501-1514$. 
